\title{
Evaluation of the effect of crude groundnut oil and on internal quality characteristics of white leghorn hen egg at room and refrigeration temperatures
}

\author{
S.S. CHAUHAN
}

\begin{abstract}
A total of 164 infertile eggs of a single strain of white leghorn of same age and reared in cages under identical conditions of feeding and management were procured from Central Avian Research Institute Izatnagar, Bareilly (U.P.).Remaining 164 eggs were divided into four groups, each comprising of 41 eggs.Initial qualities of egg in respect of albumen index, yolk index, Haugh unit were recorded.Both oiled and untreated eggs were kept at room and refrigeration temperatures. Crude groundnut oil proved good and superior to control at both the atmospheric conditions under observations. The crude groundnut oil treated eggs increased shelf-life to 28 days at room temperature and 75 days at refrigeration temperature while the control eggs have the shelf life of 14 days at room temperature and 60 days at refrigeration temperature.
\end{abstract}

KEY WORDS : Albumen index, Yolk index, Haugh unit

HOW TO CITE THIS PAPER : Chuhan, S.S. (2015). Evaluation of the effect of crude groundnut oil and on internal quality characteristics of white leghorn hen egg at room and refrigeration temperatures. Res. J. Animal Hus. \& Dairy Sci., 6(1) : 57-60.

Address for correspondence :

S.S. Chauhan, Department of Livestock Production and Management, College Veterinary Science and Animal Husbandry, N.D. University of Agriculture and technology, Kumarganj, FAIZABAD (U.P.) INDIA 